\title{
Two-Parameter Gamma-Based SUH Derivation
}

\author{
P. R. Patil, S. K. Mishra, Nayan Sharma, and A. K. Swar
}

\begin{abstract}
A simple procedure is suggested to compute direct runoff hydrograph (DRH) using an improved two-parameter gamma distribution (2PGD) based synthetic unit hydrograph (SUH) and it is tested on several storm events recorded in 3 different hydrometeorological catchments. When compared, the computed hydrographs were more accurate than those due to popular Gray, SCS, and Snyder methods, because of avoidance of manual, subjective, and tiresome fitting of hydrograph through few data points for their adjustments for unit runoff volume. The improved 2PGD incorporates the available approximate, but accurate, empirical relations for estimation of $\beta$ and $\lambda$ factors governing the shape of the dimensionless unit hydrograph (UH) from the Nash parameter number of reservoirs $(n)$. The SUH peak discharge per unit area per unit effective rainfall $\left(q_{p}\right)$ and time to peak $\left(t_{p}\right)$ have been derived from hydrologic and geomorphologic characteristics of the watershed, which is advantageous for field use. The objective of this paper is to propose a 2PGD-based method, test it on the data of 3 watersheds, and finally carry out a sensitivity analysis for model parameters. Model results during calibration and validation are very promising with average efficiency of each watershed exceeding $92 \%$ and $72 \%$, respectively.
\end{abstract}

Index Terms-Direct runoff hydrograph, Gamma distribution, Synthetic unit hydrograph, Unit hydrograph.

\section{INTRODUCTION}

Routine measurements of runoff are often scanty, and therefore, unit hydrograph (UH) for ungauged catchments are derived using synthetic unit hydrograph (SUH) models dependent on catchment characteristics [18], [10]. The prominent approaches to synthesize UH are due to [18], [19], and [8]. These methods specify a few selected points on UH through which a curve is fitted by trial and error, which is subjective and tiresome for satisfying the unit volumetric condition. In these methods graphs or equations are provided to determine values of attributes such as peak flow rate, lag or rise time, base time, and hydrograph widths, $W_{50}$ and $W_{75}$. These reasons coupled with the fact that a UH can reasonably be represented by a gamma distribution comprise the basis for its fitting.

References [11], [12], and [6] derived 2PGD from a cascade of $n$-linear reservoirs of equal storage coefficient $K$, known as instantaneous unit hydrograph (IUH) for a watershed. Since then, the gamma distribution is most commonly used in various forms depending on the discernible boundary conditions, such as peak and time to

Manuscript received September 3, 2012; revised October 27, 2012.

P. R. Patil, S. K. Mishra, and Nayan Sharma are with the Dept. of WRD\&M, Indian Institute of Technology, Roorkee, Roorkee- 247 667, U.K., India (e-mail: prpatil25@gmail.com; skm61fwt@iitr.ernet.in; nayanfwt@iitr.ernet.in).

A. K. Swar is with the State Pollution Control Board, Odisha, Bhubaneswar- 751 012, Orissa, India (e-mail: swarakhila@gmail.com). peak. The improved 2PGD-based SUH method is easy to apply and meets the UH criterion of unity. The method can do away with the calculations for $W_{50}$ and $W_{75}$. Reference [17] proposed an approximate analytical equation for calculating $n$ and $K$ (which define the shape and scale of the gamma distribution, respectively) from peak and time to peak of UH. Though the exact solution of $n$ in terms of the non-dimensional shape factor $\beta\left(=q_{p} t_{p}\right)$ is difficult to evaluate, the Nash parameter $n$ is accurately expressed mathematically in terms of $\beta$, by assuming $n$ as a non-linear function of $\beta$, eliminating trials [2]. Shape factor can be taken as the form factor that quantifies the hydrograph peakedness and influences the hydrograph shape [17]. The discrete convolution allows the computation of DRH for a given rainfall-excess and UH derived from SUH.

\section{MODEL DEVELOPMENT}

\section{A. 2PGD-Based SUH Method}

For 2PGD-based SUH derivation, [7] proposed a theoretical expression for $\mathrm{UH}$ assuming $Q$ to be proportional to $t^{x} e^{-y t}$ as follows:

$$
Q=c A y(y t)^{x} e^{-y t} / \Gamma(x+1)
$$

where $Q=$ discharge in $\mathrm{ft}^{3} / \mathrm{s}$ at time $t, A=$ drainage area $\left(\mathrm{mi}^{2}\right), x$ and $y=$ parameters that can be represented in terms of peak discharge, and $\Gamma(x+1)=$ Gamma function of $(x+1)$. With suitable change of variables and applying dimensional homogeneity, the following can be derived:

$$
\begin{gathered}
q=\frac{1}{k \Gamma n}\left(\frac{t}{k}\right)^{n-1} e^{\frac{-t}{k}}, k>0, t>0 \\
\Gamma(n)=\int_{0}^{\infty} t^{n-1}-e^{(-t)}, t>0
\end{gathered}
$$

or

$$
\begin{aligned}
& \Gamma(n)=(2 \Pi)^{0.5} n^{n-0.5} e^{-n} \times \\
& \left(1+\frac{1}{12 n}+\frac{1}{288 n^{2}}-\frac{139}{51840 n^{3}}+\frac{571}{2488320 n^{4}}\right)
\end{aligned}
$$

where $n$ and $K$ are parameters that define the shape and scale of the gamma distribution; $\Gamma(n)$ is the gamma function of $n$, which equals $(n-1) ! ; e$ is the base-number of Napierian logarithm; and $q$ is the IUH (runoff depth resulting from effective rainfall in the form of Dirac delta-function, $\mathrm{h}^{-1}$ ). The area under the curve defined by (2) is unity. Reference [4] related $n$ and $K$ as: 


$$
K=t_{P} /(n-1)
$$

Defining a non-dimensional parameter $\beta$ as a product of $q_{p}$ and $t_{p},(2)$ and (5) are combined into the following simpler form:

$$
\beta=q_{p} t_{p}=(n-1)^{(n-1)} e^{-(n-1)} / \Gamma(n-1)
$$

A simple numerical procedure i.e. Stirling's formula [1] was used by [2] to get an approximate solution of (6) as:

$$
\begin{aligned}
& n=5.53 \beta^{1.75}+1.04 \quad \text { for } 0.01<\beta<0.35 \\
& n=6.29 \beta^{1.998}+1.157 \text { for } \beta \geq 0.35
\end{aligned}
$$

Equations (7a) and (7b) were derived using numerical simulation and optimization, and can be used to estimate $n$ for known values of $q_{p}$ and $t_{p}$. These equations avoid the widely practiced trial-and-error solution of $n$ for given $\beta$ [17]. It is noted that $\beta$ values less than 0.01 are seldom experienced in the field [17]. To obtain an SUH, the hydrograph parameters were related to catchment characteristics [13], [21].

\section{B. Determination of Peak Discharge}

A multitude of peak flow formulae related with catchment area, e.g., Dickens formula, are available in literature and these are of the form:

$$
Q_{P}=C_{d} A^{m}
$$

where $Q_{p}=$ maximum flood peak $\left(\mathrm{m}^{3} / \mathrm{s}\right) ; A=$ catchment area $\left(\mathrm{km}^{2}\right)$; and $C_{d}, m=$ regression constants.

\section{Determination of Time to Peak Discharge}

Time to peak is estimated using the Snyder approach based on the concept of watershed lag from basin characteristics as:

$$
t_{P}=C_{t}\left(L L_{C}\right)^{0.5}
$$

where $t_{p}=$ time to hydrograph peak (h), $L=$ length of the main stream $(\mathrm{km}), L_{c}=$ length to watershed centroid from the outlet $(\mathrm{km})$, and $C_{t}$ is a regional constant representing variations in watershed slopes and storage characteristics.

\section{Derivation of X-hr UH and DRH}

The X-hr UH can be derived by averaging the known SUH ordinates at $\mathrm{X}-\mathrm{hr}$ intervals as:

$$
(X-h r U H)_{t}=\frac{1}{2}\left(S U H_{t}+S U H_{t-x}\right)
$$

In discrete time domain,

$$
Q_{n}=\sum_{m=1}^{n \leq M} P_{m} U_{n-m+1}
$$

where input is a series of ' $M$ ' pulses of constant rate. Equation (11) estimates direct runoff $Q_{n}$ for given volume of $m^{\text {th }}$ rainfall-excess pulse $P_{m}$ and UH ordinates $U_{n-m+l}$.

\section{E. Performance Evaluation}

The performance of the proposed approach is evaluated using following criteria.

\section{F.Nash-Sutcliffe Efficiency (NSE)}

The NSE [14] measures the strength of correlation between two independent variables, and expressed as:

$$
\begin{gathered}
N S E=[1-(R V / I V)] \times 100 \\
\text { where } R V=\sum_{i=1}^{n}\left(Q_{i}-\hat{Q}_{i}\right)^{2} \\
I V=\sum_{i=1}^{n}\left(Q_{i}-\overline{Q_{i}}\right)^{2}
\end{gathered}
$$

Here, $R V=$ remaining variance, $I V=$ initial variance, $Q_{i}=$ observed runoff for $i^{\text {th }}$ pulse $\left(\mathrm{m}^{3} / \mathrm{s}\right), \hat{Q}_{i}=$ computed runoff for $i^{\text {th }}$ pulse $\left(\mathrm{m}^{3} / \mathrm{s}\right), n=$ total number of observations, and $\bar{Q}_{i}$ $=$ overall mean runoff of storm event $\left(\mathrm{m}^{3} / \mathrm{s}\right)$. Efficiency varies at the scale of 0 to 100. It can also assume a negative value if $R V>I V$, implying that the variance in the observed and computed values is greater than the model variance. The efficiency of 100 implies a perfect fit between the observed and computed values.

\section{G. Relative Error (RE)}

The RE computes the deviation between the observed and simulated values with respect to the observed value as:

$$
R E=\left[\left(X_{o b s}-X_{c o m p}\right) / X_{o b s}\right] \times 100
$$

Here, $X_{o b s}=$ observed value and $X_{\text {comp }}=$ computed value. A high value of $\mathrm{RE}$ indicates greater deviation from the observed, and vice versa.

\section{APPLICATION}

\section{A. Study Area and Data Used}

Three watersheds were selected for application of proposed approach, (Fig. 1). The hydroclimatic and physiographic details of selected watersheds are given in Table I. Notations (C) and (V) indicate number of storm events used for calibration and validation, respectively.

The hydrograph parameters (i.e. $q_{p}$ and $t_{p}$ ) were derived from physical catchment characteristics, viz., catchment area $(A)$, and mainstream lengths ( $L$ and $L_{c}$ ) which are available from literature. Based on area, the watersheds can be categorized as to lie in the range from micro $\left(0.0003 \mathrm{~km}^{2}\right.$, Cincinnati) to river basin $\left(823.62 \mathrm{~km}^{2}\right.$, $3 \mathrm{f}$ sub-zone Godavari). 3f sub-zone Godavari has longest mainstream lengths, $L=61.08 \mathrm{~km}$ and $L_{c}=22.54 \mathrm{~km}$ as compared to Cincinnati, $L=0.024 \mathrm{~km}$ and $L_{c}=0.014 \mathrm{~km}$. Jhandoo nala watershed is the steepest (slope $=50 \%$ ) watershed while $3 \mathrm{f}$ sub-zone Godavari watershed is the mildest (slope $=0.12 \%$ ) watershed. 


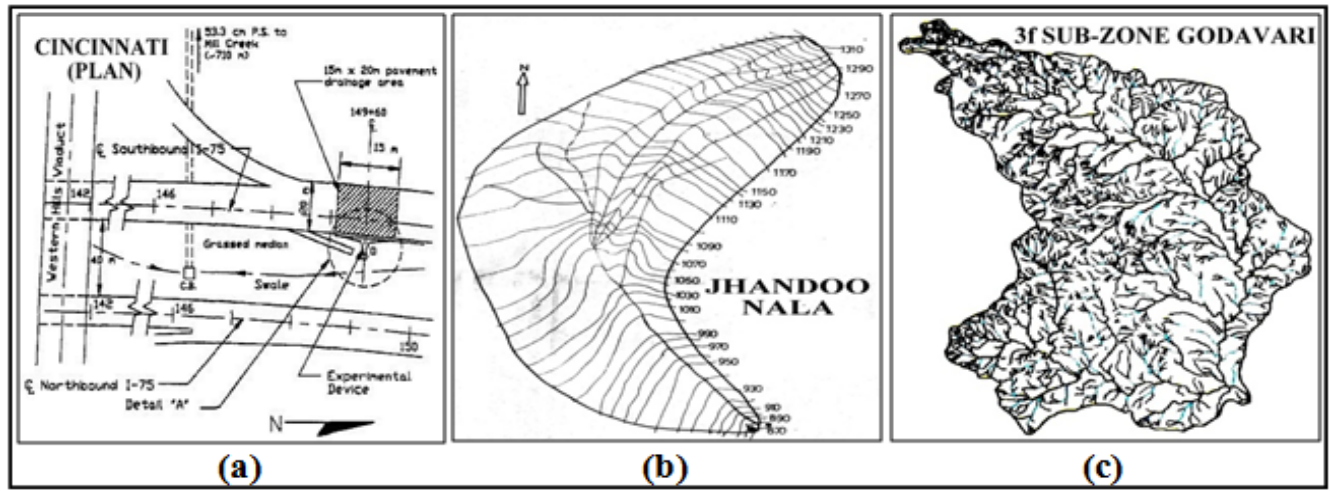

Fig. 1. Study watersheds (a) Cincinnati (plan), (b) Jhandoo nala, and (c) 3f sub-zone Godavari.

TABLE I: HYDROCLIMATIC FEATURES AND PHYSIOGRAPHIC CHARACTERISTICS OF THE STUDY WATERSHEDS

\begin{tabular}{|c|c|c|c|c|c|c|c|c|c|c|}
\hline $\begin{array}{l}\text { S. } \\
\text { no } \\
\text { (1) }\end{array}$ & $\begin{array}{c}\text { Watershed/size/location } \\
\text { (2) }\end{array}$ & $\begin{array}{l}\text { Climate } \\
\text { (3) }\end{array}$ & $\begin{array}{l}\text { Avg. } \\
\text { annual } \\
\text { rainfall } \\
(\mathrm{mm}) \\
(4)\end{array}$ & $\begin{array}{l}\text { Soil (\%) } \\
\quad(5)\end{array}$ & $\begin{array}{c}\mathrm{L} \\
\mathrm{km}) \\
(6)\end{array}$ & $\begin{array}{c}\mathrm{L}_{\mathrm{C}} \\
(\mathrm{km}) \\
(7)\end{array}$ & $\begin{array}{l}\text { Avg. } \\
\text { Land } \\
\text { slope } \\
(\%) \\
(8)\end{array}$ & $\begin{array}{l}\text { LULC } \\
(\%) \\
(9)\end{array}$ & $\begin{array}{l}\text { Source of watershed } \\
\text { details/rainfall-runoff } \\
\text { data } \\
\text { (10) }\end{array}$ & $\begin{array}{c}\text { No. of } \\
\text { events } \\
\text { used } \\
(11)\end{array}$ \\
\hline 1 & $\begin{array}{c}\text { Cincinnati }\left(0.0003 \mathrm{~km}^{2}\right) \\
\text { Asphalt pavement at milestone } \\
2.6 \text { of I-75, Cincinnati, Ohio } \\
\text { River, U.S.A. }\end{array}$ & $\begin{array}{c}\text { Climatic } \\
\text { Transition } \\
\text { Zone }\end{array}$ & 1020 & $\begin{array}{l}\text { Asphalt } \\
\text { Pavement } \\
=100\end{array}$ & 0.024 & 0.014 & 0.4 & $\mathrm{UR}=100$ & {$[16]$} & $\begin{array}{l}\text { C: } 4 \\
\text { V: } 3\end{array}$ \\
\hline 2 & $\begin{array}{c}\text { Jhandoo nala }\left(0.177 \mathrm{~km}^{2}\right) \text {, } \\
\text { Baldi River, Dehradun, } \\
\text { Uttarakhand, India } \\
\left(32^{\circ} 23^{0} \text { and } 32^{\circ} 23^{1 / 2^{0}} \mathrm{~N}\right) \\
\left(78^{\circ} 7^{1} 2^{0} \text { and } 78^{\circ} 8^{0} \mathrm{E}\right)\end{array}$ & Temperate & 2624 & $\begin{array}{c}\mathrm{SL}=50 \\
\mathrm{SICL}=50\end{array}$ & 0.900 & 0.430 & 50 & $\begin{array}{c}\mathrm{OS}=49 \\
\mathrm{WL}=47 \\
\mathrm{AG}=4\end{array}$ & [9] & $\begin{array}{l}\text { C: } 7 \\
\text { V: } 7\end{array}$ \\
\hline 3 & $\begin{array}{c}\text { 3f sub-zone Godavari, } \\
\left(823.62 \mathrm{~km}^{2}\right), \text { India } \\
\left(17^{\circ} \text { and } 23^{\circ} \mathrm{N}\right) \\
\left(76^{\circ} \text { and } 83^{\circ} \mathrm{E}\right) \\
\end{array}$ & Humid & 1300 & $\begin{array}{c}\mathrm{S} \\
\mathrm{L} \\
\mathrm{CL}\end{array}$ & 61.08 & 22.54 & 0.124 & $\begin{array}{l}\mathrm{FO}=50 \\
\mathrm{AG}=25 \\
\mathrm{WL}=25\end{array}$ & $\begin{array}{l}{[3]} \\
{[20]}\end{array}$ & $\begin{array}{l}\text { C: } 4 \\
\text { V: } 4\end{array}$ \\
\hline
\end{tabular}

Note: $\mathrm{CL}=$ Clay loam; $\mathrm{SL}=$ Sandy loam; $\mathrm{L}=\mathrm{Loam} ; \mathrm{S}=\mathrm{Sand} ; \mathrm{SICL}=$ Silty clay loam; $\mathrm{LULC}=$ Land use/Land cover; AG=Agriculture; FO=Forest; UR=Urban; $\mathrm{OS}=$ Orchard/Open scrub; WL=Waste land; $\mathrm{C}=$ Calibration; $\mathrm{V}=$ Validation.

\section{ANALYSIS AND DiscuSSION OF RESULTS}

\section{A. Determination of Rainfall-Excess and Direct Runoff}

The effectiveness of IUH models depends on the conversion of rainfall volume to runoff volume, and therefore, it is necessary to separate the rainfall-excess hyetograph from the infiltration and observed DRH from the base flow [15]. The phi-index is determined by trial-and-error [5], such that

$$
r_{d}=\sum_{m=1}^{M}\left(R_{m}-\Phi \Delta t\right)
$$

where $R_{m}=$ observed rainfall depth in $\mathrm{mm}$ or $\mathrm{cm}$ over the time interval $m, r_{d}=$ direct runoff depth in mm or cm over the watershed, $\Phi=$ phi-index over the time interval length $\Delta t$ $(\mathrm{mm} / \mathrm{hr}$ or $\mathrm{cm} / \mathrm{hr}$ ), and $M=$ number of non-zero pulses of rainfall-excess.

\section{B. Development of SUHS}

SUH derivation requires $q_{p}\left(\mathrm{~h}^{-1}\right)$ and $t_{p}(\mathrm{~h})$ to be known apriory. Based on their determination, proposed procedure involves computation of $q_{p}\left(\mathrm{~h}^{-1}\right)$ from maximum flood peak $Q_{p}\left(\mathrm{~m}^{3} / \mathrm{s}\right)$ estimated using a regional $Q_{P}-A$ relationship and $t_{p}$ (h) using Snyder approach. This procedure has been calibrated using 15 of the total 29 randomly selected storm events, and validated on the remaining events. The notations (O) and (C) indicate observed and computed values of different variables, respectively. The procedure is explained, as an example, for event (4) of Jhandoo nala watershed, as follows:

For deriving a Gamma SUH (2) from known $A, L$, and $L_{c}$, the regional $Q_{P}-A$ relationship (8) is used along with Snyder approach (9). Regional $Q_{P}-A$ relationship estimates the maximum flood peak $Q_{p}$ from known catchment area $A=$ $0.177 \mathrm{~km}^{2}$ (Table I) with regression constants $C_{d}=0.79$, and $m=0.75$ (Table II). This estimated $Q_{p}$ yields $q_{p}=0.88 \mathrm{~h}^{-1}$ (Table II). Snyder approach uses $C_{t}=0.33$ to estimate $t_{p}=$ $0.25 \mathrm{~h}$ (Table II) from known $L=0.900 \mathrm{~km}$, and $L_{c}=0.430$ $\mathrm{km}$ (Table I). The resulting parameters are $K=0.58$ (5), $\beta=$ $q_{p} t_{p}=0.22(6)$, and $\mathrm{n}=1.43(7 \mathrm{a})$. The consequent NSE is quite high $(=98.05 \%)$, indicating excellent fit (Fig. 2). The relative errors in observed and computed runoff volumes, peaks, and time to peaks are $4.31 \%, 0.44 \%$, and 0 , respectively (Table II). The computed discharges in both rising and receding phases are slightly underestimated, leading to the volumetric overestimation at the start of receding phase and at tail end with gradual decrease in discharge.

Similarly, DRH for a storm event (4) of Cincinnati watershed is derived using $q_{p}=4.37 \mathrm{~h}^{-1}$ and $t_{p}=0.08 \mathrm{~h} \mathrm{(Table}$ II). The resulting efficiency $(=88.29 \%)$ indicates a satisfactory fit (Fig. 3). The relative errors in observed and computed runoff volumes, peaks, and time to peaks are $8.11 \%, 15.82 \%$, and $11.11 \%$, respectively, which are relatively high as compared to the previous event. 
TABLE II: CALIBRATION RESULTS

\begin{tabular}{|c|c|c|c|c|c|c|c|c|c|c|c|c|c|c|c|c|}
\hline \multirow{2}{*}{ 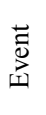 } & \multirow{2}{*}{$\begin{array}{l}\Delta \mathrm{t} \\
(\mathrm{h})\end{array}$} & \multirow{2}{*}{$\begin{array}{l}\text { Max. } \\
\text { RE } \\
(\mathrm{mm})\end{array}$} & \multirow{2}{*}{$\mathrm{C}_{\mathrm{d}}$} & \multirow{2}{*}{$\underset{\left(h^{-1}\right)}{q_{p}}$} & \multirow{2}{*}{$\mathrm{C}_{\mathrm{t}}$} & \multirow{2}{*}{$\begin{array}{c}\mathrm{t}_{\mathrm{p}} \\
(\mathrm{h})\end{array}$} & \multicolumn{2}{|c|}{ Vol. $\left(\mathrm{m}^{3}\right)$} & \multirow{2}{*}{$\begin{array}{c}\eta \\
(\%)\end{array}$} & \multicolumn{2}{|c|}{ Peak $\left(\mathrm{m}^{3} / \mathrm{s}\right)$} & \multicolumn{2}{|c|}{ Time to Peak (h) } & \multicolumn{3}{|c|}{ RE (\%) } \\
\hline & & & & & & & $(\mathrm{O})$ & (C) & & (O) & (C) & $(\mathrm{O})$ & (C) & Vol. $\left(\mathrm{m}^{3}\right)$ & $\mathrm{Q}_{\mathrm{p}}(\mathrm{m} 3 / \mathrm{s})$ & $t_{p}(h)$ \\
\hline \multicolumn{17}{|c|}{ Cincinnati } \\
\hline 1 & 0.02 & 1.67 & 2.31 & 37.86 & 0.17 & 0.02 & 9.64 & 9.08 & 93.98 & 5.E-03 & 6.E-03 & 0.62 & 0.63 & 5.88 & -20.71 & -2.70 \\
\hline 2 & 0.02 & 0.87 & 1.41 & 44.37 & 0.15 & 0.01 & 2.77 & 2.59 & 95.74 & 4.E-03 & 4.E-03 & 0.75 & 0.75 & 6.80 & 0.31 & 0.00 \\
\hline 3 & 0.03 & 0.39 & 0.12 & 8.18 & 0.51 & 0.05 & 0.12 & 0.11 & 93.95 & 2.E-04 & 3.E-04 & 0.23 & 0.20 & 4.12 & -9.77 & 14.29 \\
\hline 4 & 0.08 & 0.14 & 0.02 & 4.37 & 0.91 & 0.08 & 0.13 & 0.12 & 88.29 & 1.E-04 & 1.E-04 & 0.75 & 0.67 & 8.11 & 15.82 & 11.11 \\
\hline \multicolumn{17}{|c|}{ Jhandoo nala } \\
\hline 1 & 0.17 & 1.43 & 0.88 & 3.41 & 0.12 & 0.09 & 253 & 196 & 92.57 & 0.15 & 0.14 & 0.83 & 0.83 & 22.23 & 4.44 & 0.00 \\
\hline 2 & 0.17 & 1.09 & 0.34 & 1.71 & 0.18 & 0.14 & 194 & 174 & 94.73 & 0.07 & 0.08 & 1.33 & 1.33 & 10.15 & -10.53 & 0.00 \\
\hline 3 & 0.17 & 1.96 & 0.62 & 1.76 & 0.39 & 0.29 & 347 & 344 & 94.23 & 0.17 & 0.15 & 2.50 & 2.33 & 0.97 & 10.43 & 6.67 \\
\hline 4 & 0.17 & 4.95 & 0.79 & 0.88 & 0.33 & 0.25 & 877 & 839 & 98.05 & 0.21 & 0.21 & 0.67 & 0.67 & 4.31 & 0.44 & 0.00 \\
\hline 5 & 0.17 & 1.54 & 0.93 & 3.34 & 0.12 & 0.09 & 272 & 215 & 93.73 & 0.15 & 0.15 & 1.17 & 1.17 & 21.07 & -5.62 & 0.00 \\
\hline 6 & 0.17 & 0.55 & 0.15 & 1.53 & 0.24 & 0.18 & 97 & 90 & 95.57 & 0.05 & 0.04 & 0.83 & 0.83 & 7.01 & 15.34 & 0.00 \\
\hline 7 & 0.17 & 7.75 & 0.66 & 0.47 & 0.93 & 0.70 & 2214 & 2185 & 88.43 & 0.35 & 0.28 & 3.17 & 3.17 & 1.33 & 20.13 & 0.00 \\
\hline \multicolumn{17}{|c|}{ 3f sub-zone Godavari } \\
\hline 1 & 1.00 & 4.31 & 0.86 & 0.13 & 0.35 & 3.10 & 8.E+06 & $8 . \mathrm{E}+06$ & 95.43 & 250 & 249 & 8.00 & 9.00 & 0.70 & 0.20 & -12.50 \\
\hline 2 & 1.00 & 5.25 & 1.02 & 0.13 & 0.52 & 4.53 & 7.E+06 & 7.E+06 & 97.94 & 255 & 247 & 7.00 & 8.00 & 0.31 & 3.19 & -14.29 \\
\hline 3 & 1.00 & 1.17 & 0.15 & 0.09 & 0.68 & 5.97 & $3 . \mathrm{E}+06$ & 3.E+06 & 86.10 & 65 & 64 & 11.00 & 12.00 & 1.18 & 2.26 & -9.09 \\
\hline 4 & 1.00 & 2.77 & 0.40 & 0.10 & 0.49 & 4.32 & 5.E+06 & 5.E+06 & 90.44 & 140 & 125 & 11.00 & 12.00 & 5.61 & 10.65 & -9.09 \\
\hline
\end{tabular}

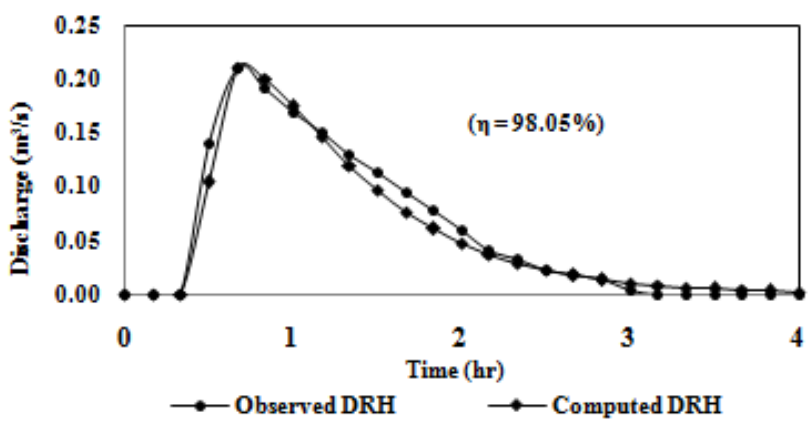

Fig. 2. Calibration of a storm event (4) of Jhandoo nala watershed.

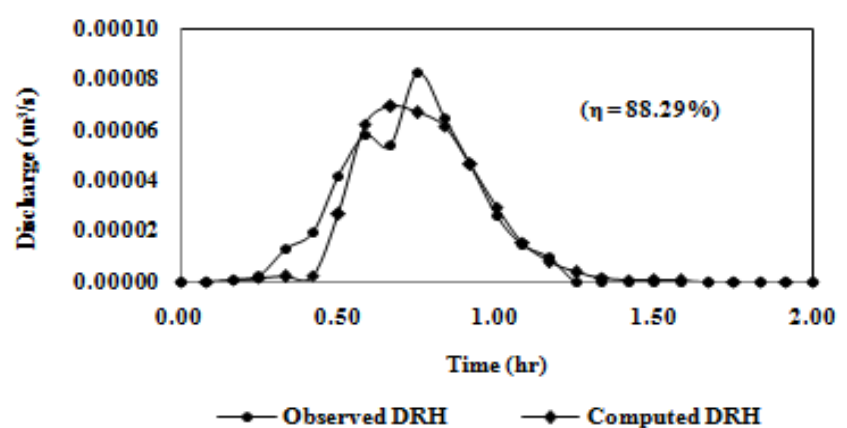

Fig. 3. Calibration of storm event (4) of Cincinnati watershed.

Calibration results of all the 15 events are shown in Table II. NSE varies from $86.10 \%$ ( $3 \mathrm{f}$ sub-zone Godavari) to 98.05\% (Jhandoo nala). The relative errors in observed and computed runoff volumes, peaks, and time to peaks vary from $0.31 \%$ ( $3 \mathrm{f}$ sub-zone Godavari) to $22.23 \%$ (Jhandoo nala), $0.20 \%$ (3f sub-zone Godavari) to $-20.71 \%$ (Cincinnati), and 0 (Cincinnati and Jhandoo nala) to $\pm 14.29 \%$ (Cincinnati and $3 \mathrm{f}$ sub-zone Godavari), respectively. $C_{d}$ is seen to vary from 0.02 (Cincinnati) to 2.31 (Cincinnati) whereas $\mathrm{m}$ has a constant value of 0.75 . $C_{t}$ varies from 0.12 to 0.93 for Jhandoo nala watersheds. The duration $(\Delta t)$ of the developed $\mathrm{UH} / \mathrm{DRH}$ varies from $0.02 \mathrm{~h}$ to $1 \mathrm{~h}$, and the maximum rainfall excess from 0.14 (Cincinnati) to $7.75 \mathrm{~mm}$ (Jhandoo nala).

\section{Model Validation}

For validation, the pair/set of input parameters (i.e. $q_{p}, t_{p}$, $C_{d}, m$, and $C_{t}$ ) of calibrated events was averaged and used as an input for SUH derivation (Table III). DRH computed for storm event (2) of $3 f$ sub-zone Godavari watershed from average input parameters are in close match with observed as in Fig. 4 with NSE $(=94.45 \%$, Table IV). The relative error in runoff volumes is very low $(=0.40 \%)$ compared to relative errors in peaks $(=-11.96 \%)$ and time to peaks $(11.11 \%)$, respectively. Similarly, the model is validated on storm event (2) of Cincinnati watershed as in Fig. 5, but with low efficiency $(=72.01 \%$, Table IV). The relative error in runoff volumes is $0.04 \%$, in peaks and time to peaks these errors are $21.81 \%$ and $-13.33 \%$, respectively.

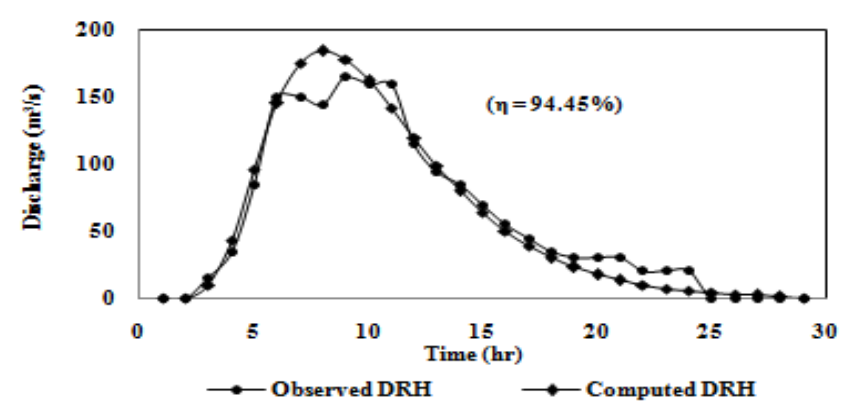

Fig. 4. Validation of storm event (2) of $3 \mathrm{f}$ sub-zone Godavari watershed.

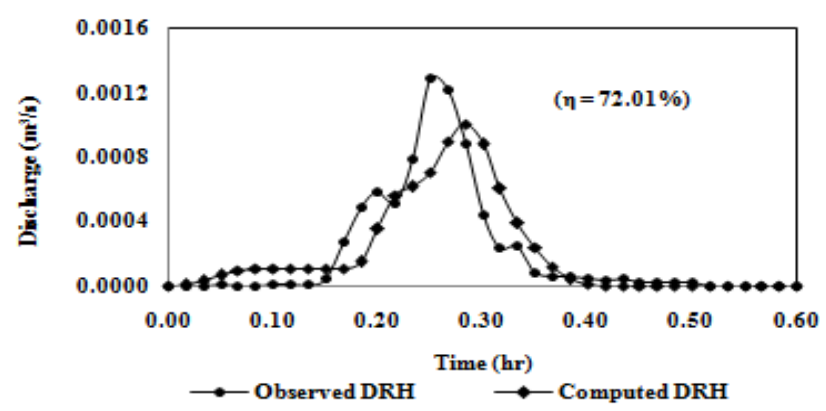

Fig. 5. Validation of storm event (2) of Cincinnati watershed. 
TABLE III: AVERAGED CALIBRATED PARAMETERS USED IN VALIDATION

\begin{tabular}{ccccccc}
\hline \hline \multirow{2}{*}{ S. No. } & Watershed & \multicolumn{5}{c}{ Averaged } \\
\cline { 3 - 7 } & & $\mathrm{C}_{\mathrm{d}}$ & $\mathrm{m}$ & $\mathrm{q}_{\mathrm{p}}\left(\mathrm{h}^{-1}\right)$ & $\mathrm{C}_{\mathrm{t}}$ & $\mathrm{t}_{\mathrm{p}}(\mathrm{h})$ \\
\hline 1 & Cincinnati & 0.97 & 0.75 & 23.70 & 0.43 & 0.04 \\
2 & 3f sub-zone Godavari & 0.61 & 0.75 & 0.11 & 0.51 & 4.48 \\
3 & Jhandoo nala & 0.62 & 0.75 & 1.87 & 0.33 & 0.25 \\
\hline \hline
\end{tabular}

The validation results of all the 14 events are shown in Table IV. As seen, the time intervals $(\Delta t)$ of the developed UH/DRHs deviate from $0.02 \mathrm{~h}$ to $1 \mathrm{~h}$, and the maximumrainfall excess from 0.01 (Cincinnati) to $8.11 \mathrm{~mm}$ (3f sub-zone Godavari). NSE varies from $63.13 \%$ (Cincinnati) to $95.58 \%$ (Jhandoo nala). Relative errors in runoff volumes, peaks, and time to peaks vary from $0.04 \%$ (Cincinnati) to $-6.94 \%$ (Cincinnati), $4.96 \%$ (Jhandoo nala) to $-61.97 \%$ (Jhandoo nala), and 0 (Cincinnati and Jhandoo nala) to $-20 \%$ (Jhandoo nala), respectively.

\section{Sensitivity Analysis}

Sensitivity analysis was performed to evaluate the impact of variation of $q_{p}$ and $t_{p}(-50 \%$ to $+50 \%$ from their original value) on NSE (Table V). $q_{p}$ is seen to be more sensitive for Cincinnati watershed whereas it is less sensitive for Jhandoo nala watershed. Similarly, $t_{p}$ is more sensitive for $3 \mathrm{f}$ sub-zone Godavari watershed whereas it is less sensitive for Jhandoo nala watershed. Overall, NSE is more sensitive to $q_{p}$ than $t_{p}$.

TABLE IV: VALIDATION RESULTS

\begin{tabular}{|c|c|c|c|c|c|c|c|c|c|c|c|c|c|c|c|c|}
\hline \multirow{2}{*}{$\begin{array}{c}\text { 节 } \\
\text { 咅 }\end{array}$} & \multirow{2}{*}{$\begin{array}{l}\Delta \mathrm{t} \\
(\mathrm{h})\end{array}$} & \multirow{2}{*}{$\begin{array}{l}\text { Max. } \\
\text { RE } \\
(\mathrm{mm})\end{array}$} & \multirow[b]{2}{*}{$\mathrm{C}_{\mathrm{d}}$} & \multirow{2}{*}{$\begin{array}{c}\mathrm{q}_{\mathrm{p}} \\
\left(\mathrm{h}^{-1}\right)\end{array}$} & \multirow[b]{2}{*}{$\mathrm{C}_{\mathrm{t}}$} & \multirow{2}{*}{$\begin{array}{l}t_{p} \\
(h)\end{array}$} & \multicolumn{2}{|c|}{ Vol. $\left(\mathrm{m}^{3}\right)$} & \multirow{2}{*}{$\begin{array}{c}\eta \\
(\%)\end{array}$} & \multicolumn{2}{|c|}{ Peak $\left(\mathrm{m}^{3} / \mathrm{s}\right)$} & \multicolumn{2}{|c|}{ Time to Peak (h) } & \multicolumn{3}{|c|}{ RE (\%) } \\
\hline & & & & & & & (O) & (C) & & (O) & (C) & (O) & (C) & Vol. $\left(\mathrm{m}^{3}\right)$ & $\mathrm{Q}_{\mathrm{p}}(\mathrm{m} 3 / \mathrm{s})$ & $t_{p}(h)$ \\
\hline \multicolumn{17}{|c|}{ Cincinnati } \\
\hline 1 & 0.02 & 1.81 & 0.97 & 23.70 & 0.43 & 0.04 & 3.88 & 3.88 & 82.34 & 7.E-03 & 7.E-03 & 0.32 & 0.35 & 0.04 & -13.37 & -10.53 \\
\hline 2 & 0.02 & 0.23 & 0.97 & 23.70 & 0.43 & 0.04 & 0.45 & 0.45 & 72.01 & 1.E-03 & 1.E-03 & 0.25 & 0.28 & 0.04 & 21.81 & -13.33 \\
\hline 3 & 0.03 & 0.01 & 0.97 & 23.70 & 0.43 & 0.04 & 0.03 & 0.03 & 63.13 & 3.E-05 & 2.E-05 & 0.20 & 0.20 & -6.94 & 23.12 & 0.00 \\
\hline \multicolumn{17}{|c|}{ Jhandoo nala } \\
\hline 1 & 0.17 & 1.56 & 0.62 & 1.87 & 0.33 & 0.25 & 277 & 270 & 95.58 & 0.12 & 0.13 & 0.50 & 0.50 & 2.33 & -6.58 & 0.00 \\
\hline 2 & 0.17 & 0.66 & 0.62 & 1.87 & 0.33 & 0.25 & 116 & 113 & 87.58 & 0.06 & 0.06 & 1.17 & 1.17 & 2.50 & 4.96 & 0.00 \\
\hline 3 & 0.17 & 2.76 & 0.62 & 1.87 & 0.33 & 0.25 & 489 & 478 & 84.91 & 0.29 & 0.23 & 0.67 & 0.67 & 2.33 & 20.18 & 0.00 \\
\hline 4 & 0.17 & 0.26 & 0.62 & 1.87 & 0.33 & 0.25 & 46 & 45 & 92.32 & 0.03 & 0.02 & 2.83 & 2.83 & 2.33 & 11.88 & 0.00 \\
\hline 5 & 0.17 & 3.84 & 0.62 & 1.87 & 0.33 & 0.25 & 680 & 664 & 77.70 & 0.26 & 0.32 & 2.00 & 2.00 & 2.33 & -22.71 & 0.00 \\
\hline 6 & 0.17 & 2.98 & 0.62 & 1.87 & 0.33 & 0.25 & 528 & 516 & 44.86 & 0.16 & 0.25 & 2.67 & 2.50 & 2.33 & -61.97 & 6.25 \\
\hline 7 & 0.17 & 3.17 & 0.62 & 1.87 & 0.33 & 0.25 & 1122 & 1096 & 72.35 & 0.64 & 0.49 & 0.83 & 1.00 & 2.33 & 22.61 & -20.00 \\
\hline \multicolumn{17}{|c|}{ 3f sub-zone Godavari } \\
\hline 1 & 1.00 & 3.22 & 0.61 & 0.11 & 0.51 & 4.48 & 5.E+06 & 5.E+06 & 67.04 & 330 & 156 & 8.00 & 7.00 & 0.86 & 52.85 & 12.50 \\
\hline 2 & 1.00 & 3.17 & 0.61 & 0.11 & 0.51 & 4.48 & $6 . \mathrm{E}+06$ & $6 . \mathrm{E}+06$ & 94.45 & 165 & 185 & 9.00 & 8.00 & 0.40 & -11.96 & 11.11 \\
\hline 3 & 1.00 & 3.67 & 0.61 & 0.11 & 0.51 & 4.48 & 7.E+06 & 7.E+06 & 92.64 & 205 & 178 & 10.00 & 11.00 & 0.40 & 13.39 & -10.00 \\
\hline 4 & 1.00 & 8.11 & 0.61 & 0.11 & 0.51 & 4.48 & 3. $\mathrm{E}+07$ & 3.E+07 & 88.57 & 700 & 632 & 8.00 & 9.00 & 0.51 & 9.76 & -12.50 \\
\hline
\end{tabular}

TABLE V: SENSITIVITY ANALYSIS OF $Q_{P}$ AND $T_{P}$

\begin{tabular}{ccccccccccccc}
\hline \hline Watershed & \multicolumn{4}{c}{ Cincinnati } & \multicolumn{4}{c}{ Jhandoo nala } & \multicolumn{3}{c}{ 3f sub-zone Godavari } \\
\% Variation & $\mathrm{q}_{\mathrm{p}}\left(\mathrm{h}^{-1}\right)$ & $\eta(\%)$ & $\mathrm{t}_{\mathrm{p}}(\mathrm{h})$ & $\eta(\%)$ & $\mathrm{q}_{\mathrm{p}}\left(\mathrm{h}^{-1}\right)$ & $\eta(\%)$ & $\mathrm{t}_{\mathrm{p}}(\mathrm{h})$ & $\eta(\%)$ & $\mathrm{q}_{\mathrm{p}}\left(\mathrm{h}^{-1}\right)$ & $\eta(\%)$ & $\mathrm{t}_{\mathrm{p}}(\mathrm{h})$ & $\eta(\%)$ \\
\hline-50 & 1.08 & 39.81 & 0.10 & 88.59 & 0.44 & 64.01 & 0.12 & 96.24 & 0.06 & 51.78 & 2.27 & 70.45 \\
0 & 2.17 & 94.48 & 0.19 & 94.48 & 0.88 & 98.05 & 0.25 & 98.05 & 0.13 & 97.94 & 4.53 & 97.94 \\
50 & 3.25 & 70.68 & 0.29 & 80.67 & 1.33 & 76.80 & 0.37 & 96.37 & 0.19 & 68.94 & 6.80 & 56.67 \\
\hline \hline
\end{tabular}

\section{CONCLUSION}

The proposed approach is much simpler than the existing cumbersome trial-and-error solution for more accurate SUH derivation as proposed method can do away with the calculations for $W 50$ and $W 75$, and easily meet the $\mathrm{UH}$ criterion of unity. Furthermore, it enables determination of SUH for ungauged watersheds with little information on A, L, and $\mathrm{L}_{\mathrm{c}}$.

\section{REFERENCES}

[1] M. Abramowitz and I. A. Stegun, Handbook of Mathematical Function, 1st ed. Dover, New York, June 1964.

[2] P. K. Bhunya, S. K. Mishra, and R. Berndtsson, "Simplified two parameter gamma distribution for derivation of synthetic unit hydrograph," Journal of Hydrologic Engineering, vol. 8, no. 4, pp. 226-230, July 2003.
[3] Central water commission, "Flood Estimation Report for Lower Godavari Subzone-3(f) (Revised)," 1995.

[4] V. T. Chow, Handbook of Applied Hydrology, 1st ed. McGraw-Hill Book Co., Inc., New York, 1964.

[5] V. T. Chow, D. R. Maidment, and L. W. Mays, Applied Hydrology, 1st ed. Mc Graw-Hill Book Co. Inc., New York, 1988.

[6] J. C. I. Dooge, "A general theory of the unit hydrograph," Journal of Geophysical Research, vol. 64, no. 2, pp. 241-256, 1959.

[7] C. G. Edson, "Parameters for relating unit hydrograph to watershed characteristics," Trans. Amer. Geophys.Un., vol. 32, no. 4, pp. 591-596, 1951.

[8] D. M. Gray, "Synthetic hydrographs for small drainage areas," J. Hydraul. Div., ASCE, vol. 87, no. 4, pp. 33-54, 1961

[9] V. S. Katiyar, "Hydrological studies of disturbed Mountainous Watersheds," Ph.D. Dissertation, Dept. Hydrology, University of Roorkee, India, June 1995.

[10] R. K. Linsley, M. A. Kohler, and J. L. H. Paulhus, Hydrology for Engineers, 3rd ed. ISE McGraw Hill, New York, 1982/1988.

[11] J. E. Nash, "The form of instantaneous unit hydrograph," International Association of Scientific Hydrology, General Assembly, Toronto, vol. 3, pp. 114-121, 1958. 
[12] J. E. Nash, "Synthetic determination of unit hydrograph parameters," Journal of Geophysical Research, vol. 64, no. 1, pp. 111-115, 1959.

[13] J. E. Nash, "A unit hydrograph study with particular reference to British catchments," in Proceedings of the Institution of Civil Engineers, vol. 17, pp. 249-282, Nov. 1960.

[14] J. E. Nash and J. V. Sutcliffe, "River flow forecasting through conceptual models, Part-I: A discussion of principles," Journal of Hydrology, vol. 10, no. 3, pp. 282-290, 1970.

[15] B. Saghafian, "Nonlinear transformation of unit hydrograph," Journal of Hydrology, vol. 330, no. 3-4, pp. 596-603, 2006.

[16] J. J. Sansalone and S.G. Buchberger, "Partitioning and first flush of metals in urban roadway storm water," $J r$. of Environmental Engineering, $A S C E$, vol. 123, no. 2, pp. 134-143, 1997.

[17] S. K. Singh, "Transmuting synthetic unit hydrographs into gamma distribution," Journal of Hydrologic Engineering, ASCE, vol. 5, no. 4 pp. $380-385$, Oct. 2000

[18] F. F. Snyder, "Synthetic Unit Graphs," Transactions - American Geophysical Union, $19^{\text {th }}$ annual meeting, pp. 447-454, 1938.

[19] SCS, "National Engineering handbook," Soil Conservation Service, U.S.D.A., Washington, D.C, 1972/1985(Revised).

[20] A. Tyagi, R. D. Singh, and R. K. Nema, "Derivation of Nash model based unit hydrograph using Marquardt algorithm," presented at the Hindi, Nat. Conf., on Hydrology and Water Resources, National Institute of Hydrology, Roorkee, UP, India, Dec. 15-16, 1995.

[21] I. P. Wu, "Design hydrographs for small watersheds in Indiana," Journal of the Hydraulics Division, ASCE, vol. 89, no. 6, pp. 35-66, 1963.

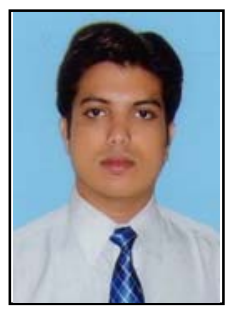

P. R. Patil was born in Roorkee, India on 25 July 1987 He got the B. TECH., Agri. Engg., Mahatma Phule Krishi Vidyapeeth, Rahuri, Maharashtra, India, 2008. M. TECH., Agri. Engg. (WRD\&M), IIT, Kharagpur, W.B., India, 2010. He is Ph.D Research Scholar at Dept. of WRD\&M, IIT, Roorkee, U.K., India.

His research interest is Surface Water Hydrology with a focus on Rainfall Runoff Modelling for development of an Synthetic Unit Hydrograph methods.

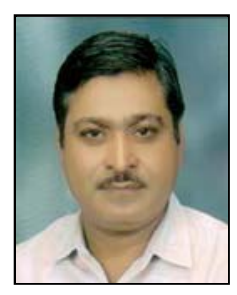

S. K. Mishra was born in Roorkee, India on 2 August 1961. He got the B.E., Civil Engg., MNREC, University of Allahabad, U.P., India, 1984. M. TECH., Civil Engg. (Hydraulics and Water Resources), IIT, Kanpur, U.P., India, 1986. Ph.D, Hydrology, IIT Roorkee (formerly University of Roorkee), U.K., India, 1999. Post-Doctoral Fellow, Louisiana State University, USA, May 22, 2000 - May 21, 2001.He is Associate Prof. at Dept. of WRD\&M, IIT Roorkee, UK, India. He has worked as Scientist at NIH Roorkee and as Visiting Faculty at IIT Bombay.

His Research Interest are: SCS-CN methodology, Reservoir operation, Rainfall-Runoff Modelling, Dam Break Studies, Flow Routing, Irrigation and Drainage Engineering, Flood forecasting.

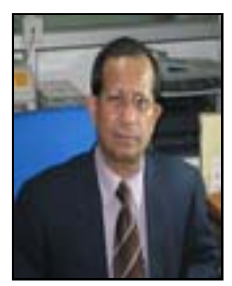

Nayan Sharma was born in Roorkee, India on 20 February 1950. He got the B.E., Civil Engg., Gauhati University, Assam, India, 1972. P.G. Dip., WRD, IIT Roorkee (formerly University of Roorkee), U.K., India, 1978. M.E., WRD, IIT Roorkee, U.K., India, 1979. Ph.D., WRD, IIT Roorkee, U.K., India, 1995. He is Prof. \& HOD of WRD\&M, IIT Roorkee, U.K., India. He has worked as an Assistant Engineer, Guest Lecturer, Assistant Prof., Associate Prof., and Visiting Prof at different institutions.

His Research Interest are: River Engineering / Management, Hydraulic Structures, Irrigation Management, Watershed Management and Modelling, River Training Works, Sediment Extractors, Climate Change, etc.

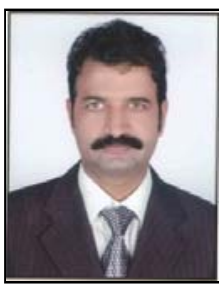

A. K. Swar was born in Bhubaneswar, India on 1 January 1962. He got the B.E., Civil Engg., College of Engineering \& Technology, Bhubaneswar, Odisha, India, 1985. M.E. (Environmental), AIT, Bangkok, Thailand, 1990. Ph.D, Environmental Engg., REC, Rourkela, Sambalpur University, Odisha, India, 2003. $\mathrm{He}$ is Senior Environmental Engineer of the State Pollution Control Board, Odisha, Bhubaneswar, India.

His Research Interest are: Online monitoring of water and waste water and surface runoff study inside industrial area. 